\title{
A survey of cardinalfish (Apogonidae) of Antsira- nana Bay, northern Madagascar
}

\author{
Josephine Pegg', Mark Steer' and Elise M. S. Belle'
}

\author{
Correspondence: \\ Elise M.S. Belle \\ The Society for Environmental Exploration \\ 50-52 Rivington Street, London, EC2A 3QP, U.K. \\ E-mail: research@frontier.ac.uk
}

\begin{abstract}
The cardinalfish of Antsiranana Bay, northern Madagascar, were surveyed over an 11 month period by underwater census employing a simple search pattern using self-contained underwater breathing apparatus. Over this period 15 species were observed including one species not previously recorded in Madagascar, Siphamia versicolor. Whilst some species were ubiquitous across sites within the bay others appeared only as single records. Cardinalfish communities were compared between sites within the bay using PRIMER 6 (Plymouth Routines In Multivariate Ecological Research) and on a national scale against existing records. Overall the species richness of cardinalfish in Antsiranana Bay is less than that observed in other regions of Madagascar. The reasons behind these regional variations include oceanic currents, temperature, depth, disturbance and sedimentation, a recognised threat to Madagascar's marine communities. This final point was reaffirmed by comparison of cardinalfish communities between sites within the bay which revealed little variation in species composition between sites, with the exception of highly-sedimented sites in the north-east of the bay that had a significantly different cardinalfish fauna to the rest. As a family that rely on the complexity of the coral reef for shelter, and exhibit high site fidelity, examination of cardinalfish communities may provide a measure of the health of a region's reef.
\end{abstract}

\section{RÉSUMÉ}

L'inventaire des poissons de la famille des Apogonidae de la baie d'Antsiranana, dans le Nord de Madagascar a été réalisé au cours d'une période de 11 mois sous forme d'un recensement sous - marin utilisant un modèle de recherche simple en plongée en scaphandre autonome. Au cours de cette période, 15 espèces ont été observées, dont une espèce qui n'était pas encore connue de Madagascar, Siphamia versicolor. Alors que certaines espèces étaient omniprésentes dans tous les sites de la baie, d'autres n'ont été relevées qu'une seule fois. Les communautés d'Apogonidae ont été comparées entre les sites de la baie à I'aide de PRIMER 6 (Plymouth Routines in Multivariate Ecological Research) et avec d'autres données existantes à I'échelle nationale. Dans I'ensemble, la richesse en espèces
d'Apogonidae dans la baie d'Antsiranana est inférieure à celle observée dans d'autres régions de Madagascar. Les raisons de ces variations régionales peuvent être expliquées par les différences relevées sur les courants océaniques, la température, la profondeur, les perturbations et la sédimentation, cette dernière étant une menace reconnue pour les communautés marines de Madagascar. La sédimentation est ressortie dans la comparaison des communautés d'Apogonidae entre les sites de la baie qui a révélé peu de variation dans la composition des espèces entre les sites, si ce n'est que les sites présentant une sédimentation importante dans le Nord-est de la baie abritaient une faune différente des autres sites. Les Apogonidae ont besoin de trouver refuge dans la barrière de corail pour s'abriter et montrent ainsi une fidélité élevée aux sites; I'étude des communautés d'Apogonidae peut ainsi constituer une mesure de l'état des récifs d'une région donnée.

\section{INTRODUCTION}

Cardinalfish (Apogonidae) form a major component of many coastal fish assemblages, both in terms of species diversity and numerical abundance (Allen 1993). Although small in size, they form a major component of the coral reef fish community due to their high abundance (Vivien 1975). Despite their prominence on reefs, cardinalfish remain one of the least studied of the major families of reef fishes (Marnane and Bellwood 2002). Cardinalfish, which feed almost exclusively on invertebrates, are important prey for large piscivorous fish such as Serranidae, Scorpaenidae, Mullidae and Muraenidae (Vivien 1975, Chave 1978) and as such are an integral component of the reef food chain. Furthermore, as cardinalfish feed nocturnally in a range of habitats and return to restricted sites during the day, they play an important role in concentrating nutrients and energy on reefs (Marnane 2000, Marnane and Bellwood 2002).

The objectives of this study were to (i) record the species of cardinalfish present in Antsiranana Bay, (ii) compare the species in Antsiranana Bay to other regions of Madagascar, (iii) examine patterns in the distribution of cardinalfish within the Bay, and (iv) investigate the relationship between cardinalfish communities and environmental variables. 


\section{MATERIALS AND METHODS}

STUDY AREA. Antsiranana Bay is situated in the northernmost part of Madagascar, adjacent to the town of Antsiranana (formerly known as Diego Suarez). The mouth of the bay is at its eastern side, opening into the Indian Ocean (Figure 1). The bay has a variety of coral reef habitats from pristine reef to highly-sedimented areas, impacted by a variety of natural and anthropogenic factors (Browne et al. 2007). The bay experiences variable and severe wind-induced wave action caused by cyclones of varying strengths on a regular basis, and the impact of these can be observed on the coral; exposed sites possess a high percentage cover of fragmented coral and coral rubble, in particular of digitate coral forms (Jabbal et al. 2010). The bay supports an artisanal fishery, as well as a low level of tourist activities (Narozanski et al. 2011). The bay has several industrial uses; Antsiranana town has a fish canning factory, there are extensive salt pans in the south-west of the bay, and it is an important trading port (Cooke et al. 2001).

Sites were selected to provide the most comprehensive coverage practicable in the accessible part of Antsiranana bay. The criteria used in site selection were: (i) Seabed type: based on existing records of habitat type (Browne et al. 2007, Jabbal et al. 2010, Frontier unpublished data) sites were selected that represented the range of benthic conditions present within the bay. (ii) Orientation: sites were selected based on their location relative to the landmass, in order to obtain as comprehensive a spread as practicable. (iii) Practical limitation: sites were only selected that were within recreational dive limits and could be accessed on a regular basis.
SURVEY METHODOLOGY. Between August 2008 and June 2009, Scuba (self-contained underwater breathing apparatus) surveys were carried out in Antsiranana Bay to record cardinalfish presence. Fifteen reef sites were surveyed (Figure 1), which varied in their physical characteristics. Persistent north-easterly winds mean that sites $1-2$ and $10-15$ are exposed to greater wave energy than the sites close to the northern shores (3-9), which are sheltered by the landmass. The impact of these waves and additional episodic cyclone impacts have left southern shore sites with a higher percentage of coral rubble than the northern shores. As is the case in many Malagasy inshore waters (Cooke et al. 2001), sedimentation as a result of terrestrial activities occurs within the bay, with the more sheltered northeasterly sites 8 and 9 being particularly affected. Each site was visited at least three times over the study period. At each survey site, an area of approximately $800 \mathrm{~m}^{2}$ was searched for a period of 45 minutes. During this time, the species of cardinalfish observed were recorded. At each site notes were made of the habitat types present. Species were identified in situ based on pictorial and photographic references (Froese and Pauly 2000, Lieske and Myers 2002, 2004, Allen and Steene 2007) and literature of apogonid systematics was consulted (Gon 1996, Greenfield et al. 2005, Fraser 2008, Fricke et al. 2009, Fraser and Allen 2010). The taxonomic classification used here follows Eschmeyer (2011). Those species that were not easily identified in situ were collected by hand net, using clove oil anaesthetic. These individuals were photographed and morphometric measurements and meristic counts were made before being returned

$49^{\circ} 14^{\prime} \cdot$

$49^{\circ} 16^{\prime}$

$49^{\circ} 18^{\prime}$

$49^{\circ} 20^{\circ}$

$49^{\circ} 22^{\prime}$

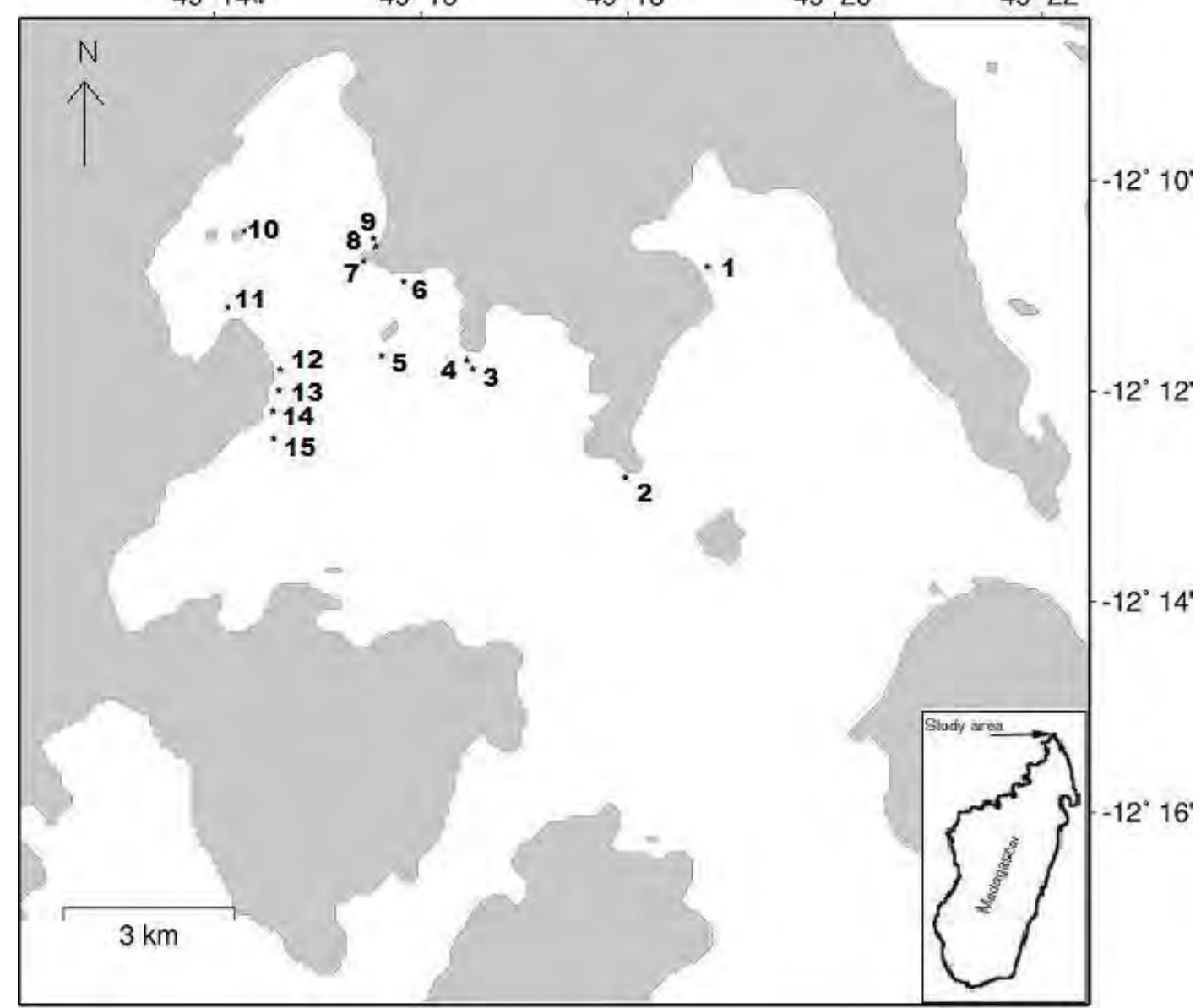

FIGURE 1. Antsiranana Bay showing location of survey sites. Landmasses are shown in grey. 
TABLE 1. Mean estimated abundance of cardinalfish at 15 survey sites. Abundance scale: $1=<10,2=10-50,3=50-100,4=100-200,5=200+$.

\begin{tabular}{|c|c|c|c|c|c|c|c|c|c|c|c|c|c|c|c|c|c|}
\hline \multirow{2}{*}{$\begin{array}{l}\text { Species (ranked by number } \\
\text { of sites at which species } \\
\text { were recorded) }\end{array}$} & \multicolumn{15}{|c|}{ Site } & \multirow{2}{*}{$\begin{array}{l}\text { Abundance at sites } \\
\text { where species present }\end{array}$} & \multirow{2}{*}{$\begin{array}{l}\text { Abundance across all } \\
15 \text { sites surveyed }\end{array}$} \\
\hline & 1 & 2 & 3 & 4 & 5 & 6 & 7 & 8 & 9 & 10 & 11 & 12 & 13 & 14 & 15 & & \\
\hline $\begin{array}{l}\text { Cheilodipterus } \\
\text { quinquelineatus }\end{array}$ & 3 & 2 & 3 & 3 & 3 & 3 & 4 & & & 2 & 3 & 2 & 2 & 3 & & frequent & occasional \\
\hline Apogon fragilis & 1 & & & & & & 4 & 5 & 4 & 1 & 1 & & & & 1 & occasional & rare \\
\hline Archamia fucata & & 2 & & & & & 2 & & & 1 & 1 & & & 2 & & occasional & rare \\
\hline Siphamia versicolor & & & 2 & 1 & & & & 2 & 2 & & & & & 1 & & occasional & rare \\
\hline Cheilodipterus artus & 1 & 2 & 1 & & 1 & & & & & & & 2 & & & & rare & rare \\
\hline Apogon thermalis & & & & & & & & 3 & 3 & & & & & & & frequent & rare \\
\hline Apogon aureus & & & & 2 & & & 3 & & & & & & & & & frequent & rare \\
\hline Apogon cyanosoma & & & & & 1 & 1 & & & & & & & & 1 & 1 & rare & rare \\
\hline Apogon leptacanthus & 1 & & & & & & & & & & 1 & & & 2 & & rare & rare \\
\hline Apogon savayensis & & 2 & & & & & & & & & & 2 & & & & occasional & rare \\
\hline Cheilodipterus macrodon & & & 2 & & & & 1 & & & & & & & & & occasional & rare \\
\hline Apogon angustatus & & & & & 1 & & & 1 & & & & & & & & rare & rare \\
\hline Apogon fraenatus & & & & & & & & & & & & & & 1 & & rare & rare \\
\hline Apogon kallopterus & & & & & & & 1 & & & & & & & & & rare & rare \\
\hline Apogon taeniophorus & 1 & & & & & & & & & & & & & & & rare & rare \\
\hline Species richness & 5 & 4 & 4 & 3 & 4 & 2 & 6 & 4 & 3 & 3 & 4 & 3 & 1 & 5 & 2 & & \\
\hline
\end{tabular}

alive to the locality from which they were removed. Voucher specimens were not collected.

At each site the number of individuals of each species per $800 \mathrm{~m}^{2}$ was estimated. Due to the highly territorial nature of cardinalfish and the uniform search pattern employed in the underwater survey, the chance of double counting of individuals was minimised. In some locations, however, cardinalfish were so populous that an absolute count would have been impossible using only visual census, therefore an estimate of abundance, i.e. estimated number of individuals of each cardinalfish species per site was recorded on an arbitrary ordinal scale. The results of repeat surveys at each site were averaged and the rounded means used in the consequent analysis.

DATA ANALYSIS. PRIMER 6 (Plymouth Routines In

Multivariate Ecological Research) was used to examine the between-site community variation. PRIMER employs univariate, graphical and multivariate methods to analyse species abun-

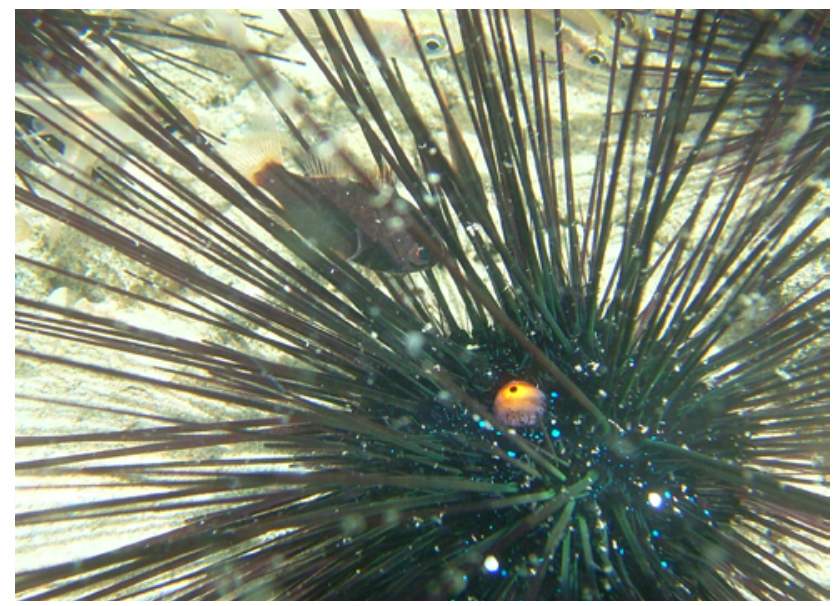

FIGURE 2. Siphamia versicolor with Diadema setosum. Photograph taken at a shallow sandy site (Site 9) where Diadema provided the majority of cover. dance data in biological monitoring of environmental impacts and show community structure (Clarke and Gorley 2006). In this study we used SIMPEROF, a methodology that identifies the species primarily providing the discrimination between two observed sample clusters. Initially, a pre-treatment was carried out on the data set; a square root transformation was applied to the data in order to downweight any dominant contributions of particularly abundant species in samples (Clarke and Gorley 2006). A resemblance matrix was then produced to show the similarities between pairs of samples using Bray-Curtis similarity; a step necessary prior to any further analysis. Bray-Curtis similarity is the most commonly used similarity coefficient for biological community analysis, as it reflects differences between samples based on community composition and total abundance (Clarke 1993). A CLUSTER dendrogram was produced, showing the hierarchical clustering of samples going into smaller numbers of groups as their similarity to each other diminish

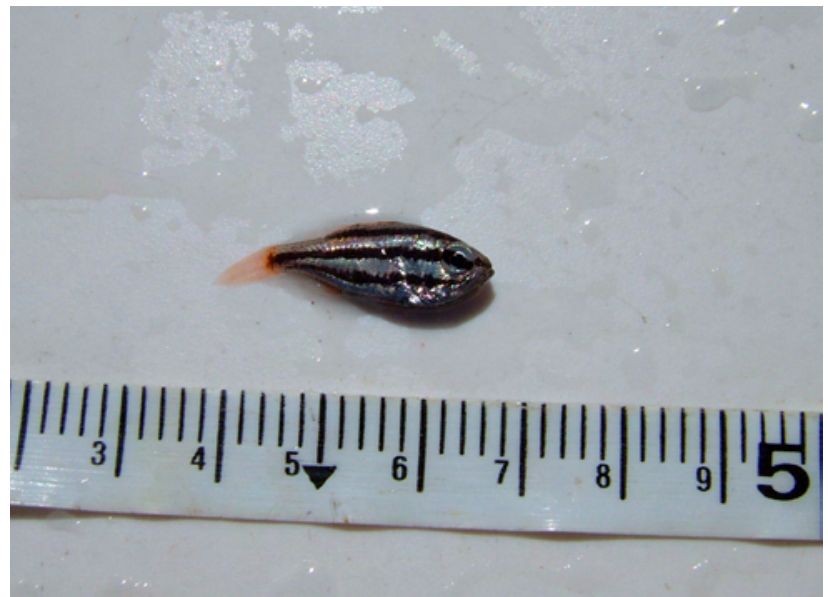

FIGURE 3. Siphamia versicolor (same individual as Figure 2). The cardinalfish appears to be red-black in colour until stressed when the lines become visible. 


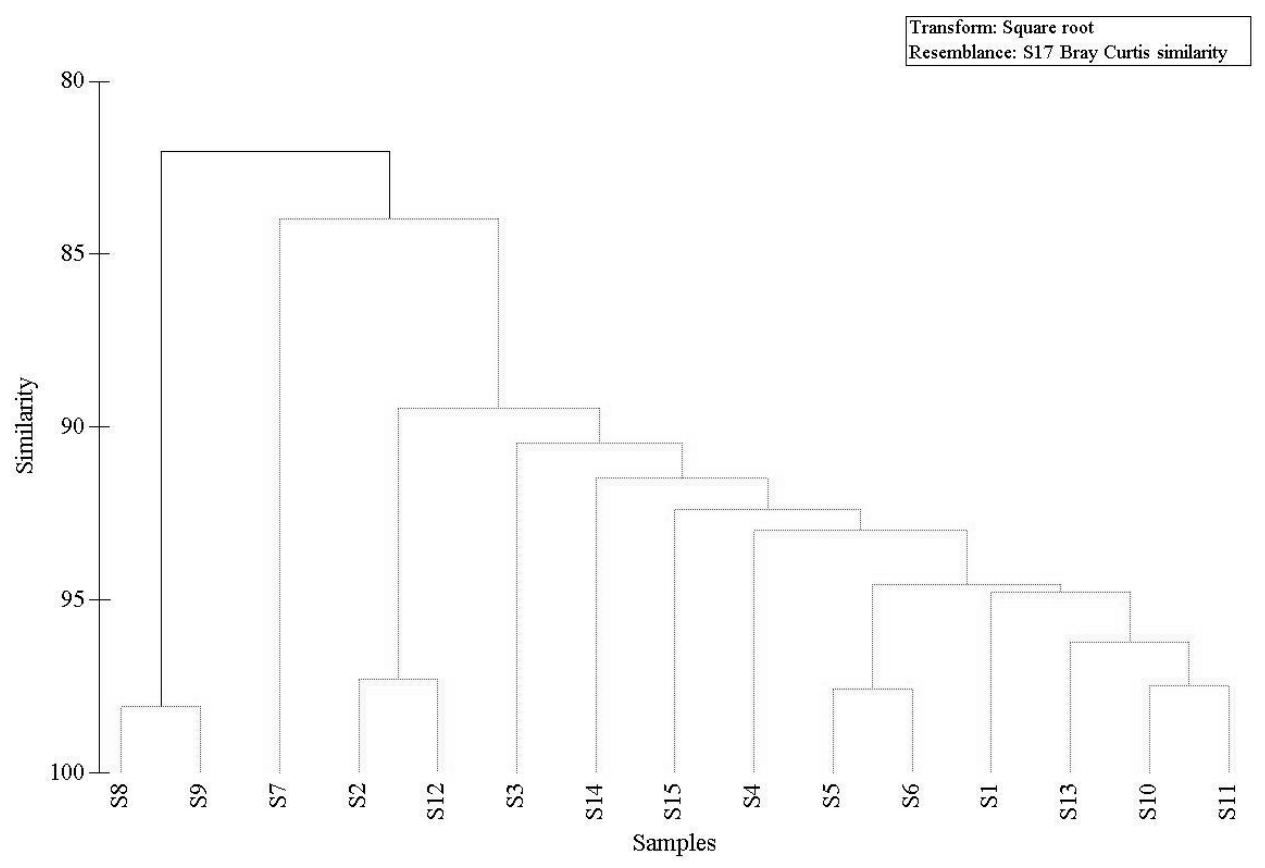

FIGURE 4. SIMPEROF analysis, carried out in PRIMER 6, showing relatedness of cardinalfish communities at the 15 study sites. A figure of 0 indicates no similarity between communities, and 100 indicates identical communities. A continuous black line indicates a significant difference.

(Clarke and Gorley 2006). A SIMPEROF test was applied to the cluster to show the statistical significance of the groupings.

\section{RESULTS}

SPECIES RECORDED. Fifteen species of cardinalfish were recorded in the course of this study (Table 1). Of these no previous records exist, to the authors' knowledge, of Siphamia versicolor in Madagascar.Individuals of the taxon thought to be siphamia versicolor were recorded amongst the spines of the long-spined sea urchin Diadema setosum. They were a dark red-black colour and very well camouflaged amongst the Diadema's spines (Figure 2); when stressed or captured, however, they became lighter and revealed three thick dark stripes on a silver body (Figure 3). They were observed across the bay in the presence of Diadema but distribution and abundance were probably underestimated due to their cryptic nature.

SPECIES DISTRIBUTIONS WITHIN ANTSIRANANA BAY.

Within Antsiranana Bay there was considerable betweensite variation in species composition (Table 1). Cheilodipterus quinquelineatus was the most widespread species, occurring at nine of the 12 sites, followed by Apogon fragilis that was recorded at seven sites. Three species were recorded only once across all sites: Apogon fraenatus, A. kallopterus and A. taeniophorus. Community structure was complex with in most cases overlap between species and sites: SIMPEROF analysis revealed that whilst in most cases there was a generally high level of similarity between cardinalfish communities within the bay (Figure 4). The communities of sites 8 and 9 were significantly different from those of the rest of the sites.

\section{DISCUSSION}

Fifteen species were recorded in Antsiranana Bay including Siphamia versicolor. The discovery of this species in Antsiranana Bay is surprising as its distribution is described as Indo-West Pacific from the Maldives to northwestern Australia (Froese and Pauly 2000); if confirmed, this record therefore extends its westerly distribution. The number of species recorded was lower in Antsiranana Bay compared to 21 in northwest Madagascar (McKenna and Allen 2005) and 20 in Toliara, southwest Madagascar (Vivien 1975) (Supplementary Material). Seven species were common to all three regions; Apogon angustatus, A. cyanosoma, A. fraenatus, A. kallopterus, Archamia fucata, Cheilodipterus macrodon and C. quinquelineatus. Antsiranana Bay and northwest Madagascar have the highest percentage of species in common (31\%), followed by the two western sites (24\%) and Antsiranana Bay and southwest Madagascar, which share the least common species (20\%).

Madagascar waters are dominated by a single current system derived from the south equatorial current (SEC) whose waters encircle much of Madagascar with a quasi-permanent gyre centred to the south of the Comoros which links the waters of northwestern Madagascar with Mozambique (Cooke et al. 2001). However, although dispersal mechanisms are in place, cardinalfish communities around the island are not homogenous as environmental parameters shape the species present. These parameters could include temperature, depth, disturbance and sedimentation.

Madagascar straddles almost $14^{\circ}$ of latitude, with mean annual open-water surface temperatures ranging from 22-28 ${ }^{\circ} \mathrm{C}$, and reaching extremes of $19^{\circ} \mathrm{C}$ in Toliara lagoons during winter (Cooke et al. 2001). The difference in shallow-water assemblages of the north and south has been attributed to this large water temperature range; cooke et al. (2001) observed that coral reef communities of Nosy Be, (within the northwest Madagascar study area of McKenna and Allen (2005)) and Toliara are visibly different, despite no systematic scientific comparison having been made. Results of the present study are consistent with this assertion.

However, despite being on similar latitude, there is still a considerable difference between the northwest community 
and that of Antsiranana Bay, which may be in part attributed to wind-induced wave action. Previous studies (Vivien 1975, Chave 1978, Greenfield and Johnson 1990) identified high wave energy as a limiting factor in cardinalfish distribution. Ralinson (1991) recorded the differences in winds between coastal regions; Toliara experienced the greatest number of days with winds less than $10 \mathrm{~km} \cdot \mathrm{h}^{-1}$ (337 days), Nosy Be had 220 days, whilst Antsiranana had only 19 days. The impact of the winds in Antsiranana Bay is considerable with waves of up to $2 \mathrm{~m}$ experienced during the windiest months of June, July and August (pers. obs.). Furthermore, cyclones have an episodic impact on Madagascar. These disturbances have been shown to affect the coral community structure; Done (1992) and Lewis (1998) showed specifically that cardinalfish are amongst the species affected by cyclones; These studies showed changes in species and numbers of individuals present following cyclonic events. cyclonic or severe wind-induced wave action can result in physical damage to, and resultant death of, live coral (Lewis 1998). In northwest Madagascar the ratio of live to dead coral is around 5:1 (Webster and McMahon 2002) whilst in Antsiranana Bay the ratio of live coral to coral rubble is $2: 3$ (Jabbal et al. 2010) Although it is possible that in the period between these studies a bleaching event may have produced the observed reduction in live coral, there is no record of such an event in the available literature. The vulnerability of corals to physical damage varies between species, yet digitate forms are most impacted (Rousseau et al. 2010), and cardinalfish are most strongly associated with these forms (Gardiner and Jones 2005).

Depth is another important determinant in all marine communities and one that has been shown to influence cardinalfish distribution, including that of the five most abundant species recorded in Antsiranana Bay (Greenfield and Johnson 1990). Although Antsiranana Bay reaches depths in excess of 30 $\mathrm{m}$ in places, it has relatively shallow coral reefs, rarely deeper than $10 \mathrm{~m}$, beyond which the seabed is barren sand. In comparison, Vivien (1975) surveyed the Toliara reefs to a maximum of 60 $\mathrm{m}$ and McKenna and Allen (2005), in northwest Madagascar, to $40 \mathrm{~m}$. It may therefore be hypothesised that the lower diversity within Antsiranana Bay is due to restricted depth. However, of the 29 species not found in Antsiranana Bay only two, Fowleria aurita (in the northwest) and Apogon flagelliferus (in the southwest) were recorded exclusively outside the depth ranges surveyed in Antsiranana Bay.

Although the 15 study sites within Antsiranana Bay are relatively closely situated, there is still a variation in the cardinalfish community between them. Within the bay, the most prominent difference, highlighted by the SIMPEROF analysis between cardinalfish populations, was between the sites in the sheltered, heavily-sedimented northeastern section of the bay and the remainder of the sites. The impact of sedimentation in structuring reef communities has been recorded in Madagascar (Cooke et al. 2001) and worldwide (e.g., Mallela et al. 2007). Cardinalfish are active by night, returning to shelter within the reef by day (Marnane and Bellwood 2002). Gardiner and Jones (2005) showed cardinalfish to be strongly associated with live digitate corals; this characteristic, coupled with their strong site fidelity (Marnane 2000), makes cardinalfish a group of fishes vulnerable to loss of habitat complexity. The fact that increased sedimentation reduces the number of reef fissures, which provide cardinalfish with daytime refugia, could explain why in heavily-sedimented areas the cardinalfish population is limited both in total numbers, due to a reduction in available space, and in diversity, supporting only those species tolerant of shelter provided primarily by Diadema setosum urchins. As a consequence, observation of cardinalfish may prove a useful tool in monitoring the health of coral reef communities.

The next course of action should be the collection of voucher specimens to validate the identifications made herein, particularly that of Siphamia versicolor, an unexpected finding. The comparison between the communities would be greatly enhanced by a contemporary survey of the Toliara reefs of southwest Madagascar. This would also provide an interesting test of the hypothesis that sedimentation alters cardinalfish communities as these reefs have been subjected to heavy sedimentation since the time of Vivien's 1975 census (Cooke et al. 2001).

\section{ACKNOWLEDGMENTS}

We wish to thank the staff, interns and research assistants of Frontier for their assistance with this research. We also acknowledge use of the Maptool program (<www.seaturtle. $\mathrm{org} / \mathrm{maptool} />$ ) to produce Figure 1. We would like to thank the three anonymous reviewers for their constructive criticisms of this manuscript.

\section{REFERENCES}

Anderson, R. C., Randall, J. E. and Kuiter, R. H. 1998. New records of fishes from the Maldive Islands, with notes on other species. Ichthyological Bulletin of the J. L. B. Smith institute of Ichthyology 67: 20-32.

Allen, G. R. 1993. Cardinalfishes (Apogonidae) of Madang Province, Papua New Guinea, with descriptions of three new species. Revue Francaise d'Aquariologie 20: 9-20.

Allen, G. R. and Steene, R. C. 2007. Indo-Pacific Coral Reef Field Guide. Tropical Reef Research, Singapore.

Browne, N. B., Markham, H., Fanning, E. and Weaver, D. 2007. Diego Suarez Bay: a proposed marine management strategy. Frontier-Madagascar Environmental Research Report 16. Society for Environmental Exploration, London and Institut Halieutique et des Sciences Marines, Toliara.

Chave, E. H. 1978. General ecology of six species of Hawaiian cardinalfishes. Pacific Science 32, 3: 245-270.

Cooke, A., Ratomhenina, O., Ranaivoson, E., and Razafindrainibe, H. 2001. Madagascar. In: Seas at the Millennium: An Environmental Evaluation. R. Sheppard (ed.), pp 113-131. Pergamon, Amsterdam.

Clarke, K. R. 1993. Non-parametric multivariate analyses of changes in community structure. Australian Journal of Ecology 18: 117-143. (doi:10.1111/j.1442-9993.1993.tb00438.x)

Clarke, K. R. and Gorley, R. N. 2006. PRIMER v6: User Manual/Tutorial. PRIMER-E, Plymouth.

Done, T. 1992. Effects of tropical cyclone waves on ecological and geomorphological structures on the Great Barrier Reef. Continental Shelf Research 12, 7-8: 859-872. (doi:10.1016/0278-4343(92)90048-0)

Eschmeyer, W. N. 2011. Catalogue of Fishes electronic version. <http:// research.calacademy.org/ichthyology/catalog/fishcatmain.asp> accessed 29 March 2011.

Fraser, T. H. 2008. Cardinalfishes of the genus Nectamia (Apogonidae, Perciformes) from the Indo-Pacific region with descriptions of four new species. Zootaxa 1691: 1-52.

Fraser, T. H. and Allen, G. R. 2010. Cardinalfish of the genus Apogonichthyoides Smith, 1949 (Apogonidae) with a description of a new species from the West-Pacific region. Zootaxa 2348: 40-56.

Fricke, R., Mulochau, T., Durvile, P., Chabanet, P., Tessier, E. and Letourneur, Y. 2009. Annotated checklist of the fish species (Pisces) of La Réunion, including a Red List of threatened and declining species. Stuttgarter Beiträge zur Naturkunde A (Biologie), Neue Serie 2: 1-168. 
Froese, R. and Pauly, D. 2000. FishBase. <www.fishbase.org > accessed 2 February 2010

Gardiner, N. M. and Jones, P. J. 2005. Habitat specialisation and overlap in a guild of coral reef cardinalfish (Apogonidae). Marine Ecology Progress Series 305: 163-175. (doi:10.3354/meps305163)

Gon, O. 1996. Revision of the cardinalfish subgenus Jaydia (Perciformes, Apogonidae, Apogon). Transactions of the Royal Society of South Africa 51, 1: 147-194. (doi:10.1080/00359199609520605)

Greenfield, D. W. and Johnson, R. K. 1990. Heterogeneity in habitat choice in cardinalfish community structure. Copeia 4: 1107-1114.

Greenfield, D. W, Langston, R. C. and Randall, J. F. 2005. Two new cardinalfishes of the Indo-Pacific fish genus Zoramia (Apogonidae). Proceedings of the California Academy of Sciences 56: 625-637.

Jabbal, J., Burton, H., Narozanski, A., Evans, E., Johnson, V., Belle, E. M. S and Fanning, E. 2010. An assessment of coral reef and mangroves in the bay of Antsiranana. Frontier-Madagascar Environmental Research Report 25. Society for Environmental Exploration, London and Institut Halieutique et des Sciences Marines, Toliara.

Lewis, A. R. 1998. Effects of experimental coral disturbance on the population dynamics of fishes on large patch reefs. Journal of Experimental Marine Biology and Ecology 230: 91-110. (doi:10.1016/S00220981(98)00087-2)

Lieske, E. and Myers, R. 2002. Coral Reef Fishes. Princeton University Press, Princeton.

Lieske, E. and Myers, R. 2004. Coral Reef Guide: Red Sea. Harper Collins, London.

Mallela, J., Roberts, C., Harrod, C. and Goldspink, C. R. 2007. Distributional patterns and community structure of Caribbean coral reef fishes within a river-impacted bay. Journal of Fish Biology 70, 2: 523-537. (doi:10.1111/j.1095-8649.2007.01323.x).

Marnane, M. J. 2000. Site fidelity and homing behaviour in coral reef cardinalfishes. Journal of fish Biology 57, 6: 1590-1600. (doi:10.1111/j.1095-8649.2000.tb02234.x)
Marnane, M. J. and Bellwood, D. R. 2002. Diet and nocturnal foraging in cardinalfishes (Apogonidae) at One Tree Reef, Great Barrier Reef, Australia. Marine Ecology Progress Series 231: 261-268. (doi:10.3354/ meps231261)

McKenna, S. A., and Allen, G. R. (eds.). 2005. A Rapid Biodiversity Assessment of the Coral Reefs of Northwest Madagascar. Bulletin of the Rapid Assessment Program 31, Conservation International, Washington, D.C.

Narozanski, A. J., Belle, E. M. S. and Steer, M. 2011. Understanding local differences in small-scale fisheries: a comparison of two fishing settlements in Antsiranana Bay, northern Madagascar. Madagascar Conservation \& Development 6, 2: 68-77. (doi:10.4314/mcd.v6i2.5).

Ralinson, A. 1991. Les potentiels des ressources halieutiques maritimes et leur niveau d'exploitation. In: Rapport du Séminaire National sur les Politiques et la Planification du Développement des Pêches à Madagascar, Antananarivo, 15-19 octobre 1990. C. Andrianaijaona, Z. Kasprzyk and G. Dasylva (eds.), pp 137-150. FAO, Madagascar.

Rousseau, Y., Galzin, R. and Marechal, J. P. 2010. Impact of hurricane Dean on coral reef benthic and fish structure of Martinique, French West Indies. Cybium 34, 3: 243-256.

Vivien, M. L. 1975. Place of apogonid fish in the food webs of a Malagasy coral reef. Micronesia 11:185-196.

Webster, F. J. and McMahon, K. M. 2002. As assessment of coral reefs in northwest Madagascar. In: Coral Reef Degradation in the Indian Ocean. O. Linden, D. Souter, D. Wilhelmsson, and D. Obura (eds.), pp. 190-201. CORDIO, Kalmar.

\section{SUPPLEMENTARY MATERIAL.}

AVAILABLE ONLINE ONLY.

SUPPLEMENTARY MATERIAL S1: Species recorded in three regions of Madagascar. 